\title{
REVIEW OF TRENCHLESS TECHNOLOGIES' SUCCESSES AND THEIR DEPENDENCE ON PRECISE GEOTECHNICAL INVESTIGATION
}

\author{
J. C. Ezeokonkwo ${ }^{1, *}$ and C. U. Nwoji ${ }^{2}$ \\ 1,2, DEPARTMENT OF CIVIL ENGINEERING, UNIVERSITY OF NIGERIA, NSUKKA. NIGERIA \\ E mail addresses: ${ }^{1}$ josephat.ezeokonkwo@unn.edu.ng, ${ }^{2}$ clifford.nwoji@unn.edu.ng
}

\begin{abstract}
Geotechnical investigators are among the first to assess the physical setting of a project. Geotechnical investigations are performed to ascertain the character and variability of the strata underlying the site of the proposed structure and to assess those properties, which may affect the performance of the structure and the choice of method of construction. Deficient geotechnical investigations, faulty interpretation of results, or failure to portray results in a clearly understandable manner may contribute to inappropriate designs; delays in construction schedules, costly construction modifications, and use of substandard borrow material, environmental damage to the site, post construction remedial work, and even failure of a structure and subsequent litigation. Trenchless technology can be defined as the use of construction methods to install and repair underground infrastructure without digging a trench or open cutting. Trenchless projects should never been seen as a simple process but should always be seen as "site specific". Geotechnical is one area in which certain characteristics can change rapidly. Knowing the subground structure that the proposed borehole is to be constructed in, can significantly alter the parameters, design and type of construction method, site location, methodology, costs and expected construction time frame needed to complete the project successfully.
\end{abstract}

Keywords: trenchless technology, geotechnical investigation, open-cut, construction techniques, project

\section{INTRODUCTION TO TRENCHLESS TECHNOLOGY}

The need to replace deteriorating underground utility infrastructure and to expand utility services increases the need for utility conduits to intersect roadways. Open-trench method is currently the most widely used method for installation of underground pipelines and conduits of all sizes. However, open-cut construction has several shortcomings, chief amongst which are: health and safety concerns of workers, surface disturbance, disruption to vehicular/pedestrian traffic and reduction of pavement life [1].

Today, other cost-effective alternatives exist to traditional open-trench construction. These methods are categorized as "Trenchless Technologies" or nodig technology as they require minimum trenching (excavation). Trenchless technology can be defined as the use of construction methods to install and repair underground infrastructure without digging a trench or open cutting [2]. NASTT defined trenchless technology as a family of methods, materials, and equipment capable of being used for the installation of new or replacement or rehabilitation of existing underground infrastructure with minimal disruption to surface traffic, business, and other activities [3].

Although considered a relatively new term, some trenchless technology methods have been practiced since the early 1900s [1]. Rapid development and expansion of trenchless technology has been observed over the past couple of decades due to the desire to cost-effectively install or rehabilitate underground infrastructure with minimal social and environmental impacts [4]. Undertaking a Trenchless project should never been seen as a simple process but should always be seen as "site specific". One area in which certain characteristics can change rapidly is Geotechnical [5]. Trenchless methods offer several potential advantages. They can reduce noise, dust, construction vibration, and other environmental impacts $[6,7]$.

\subsection{Trenchless Technology Methods}

Trenchless technologies are commonly divided into two categories: trenchless construction methods (TCM) and trenchless renewal methods (TRM). The classification of trenchless methods is shown in Figure

* Corresponding author, Tel: +234-8063063078 
1. Stidger [8] stated that a lack of understanding of methods and costs seems to be the key reason that open-cut methods are still commonly chosen for some projects. In view of the fact that focus on utility pipe work is shifting toward established urban areas with aging utility pipes, makes trenchless construction and rehabilitation methods a good option that should be considered by designers [9].

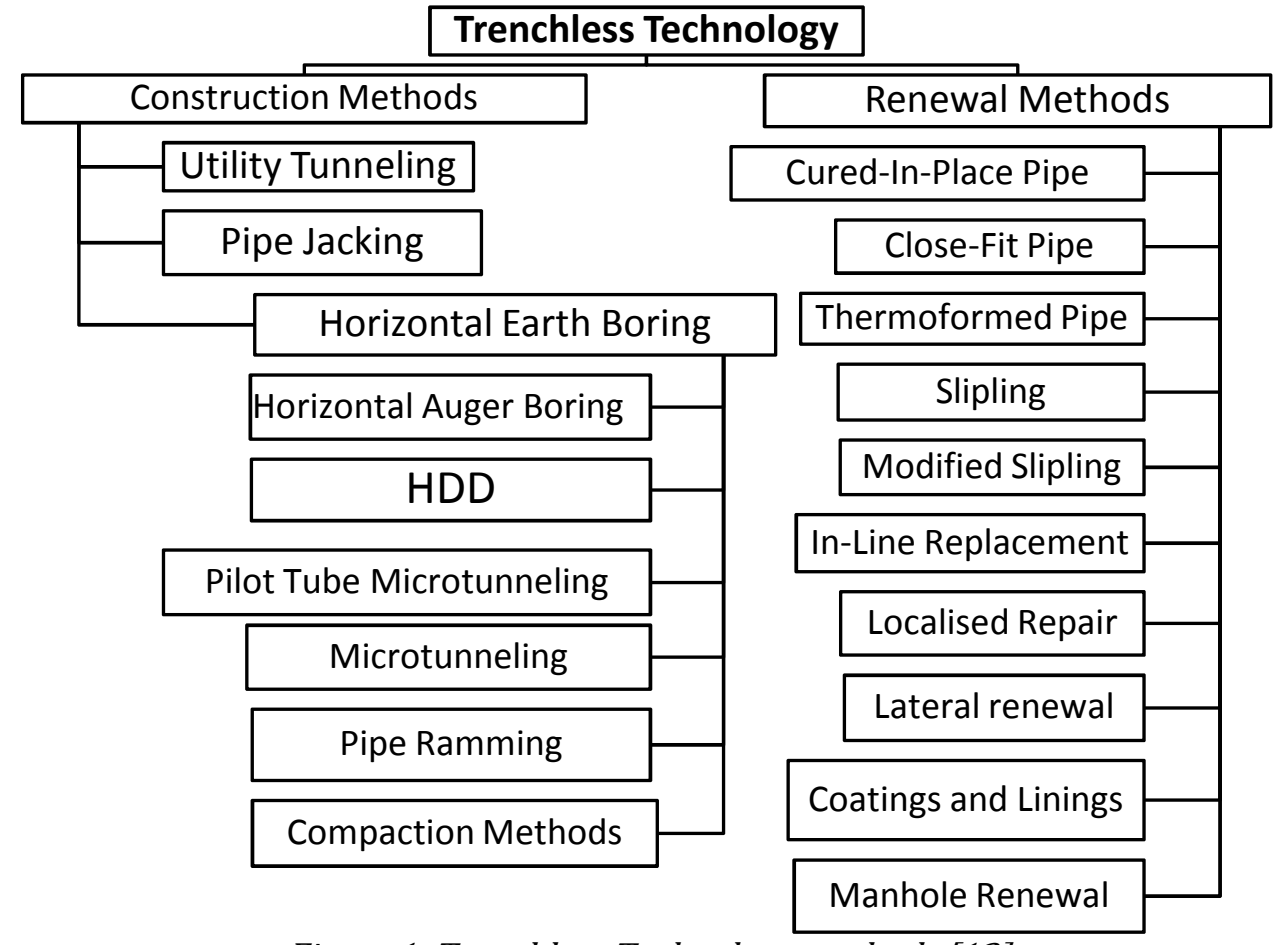

Figure 1: Trenchless Technology methods [12]

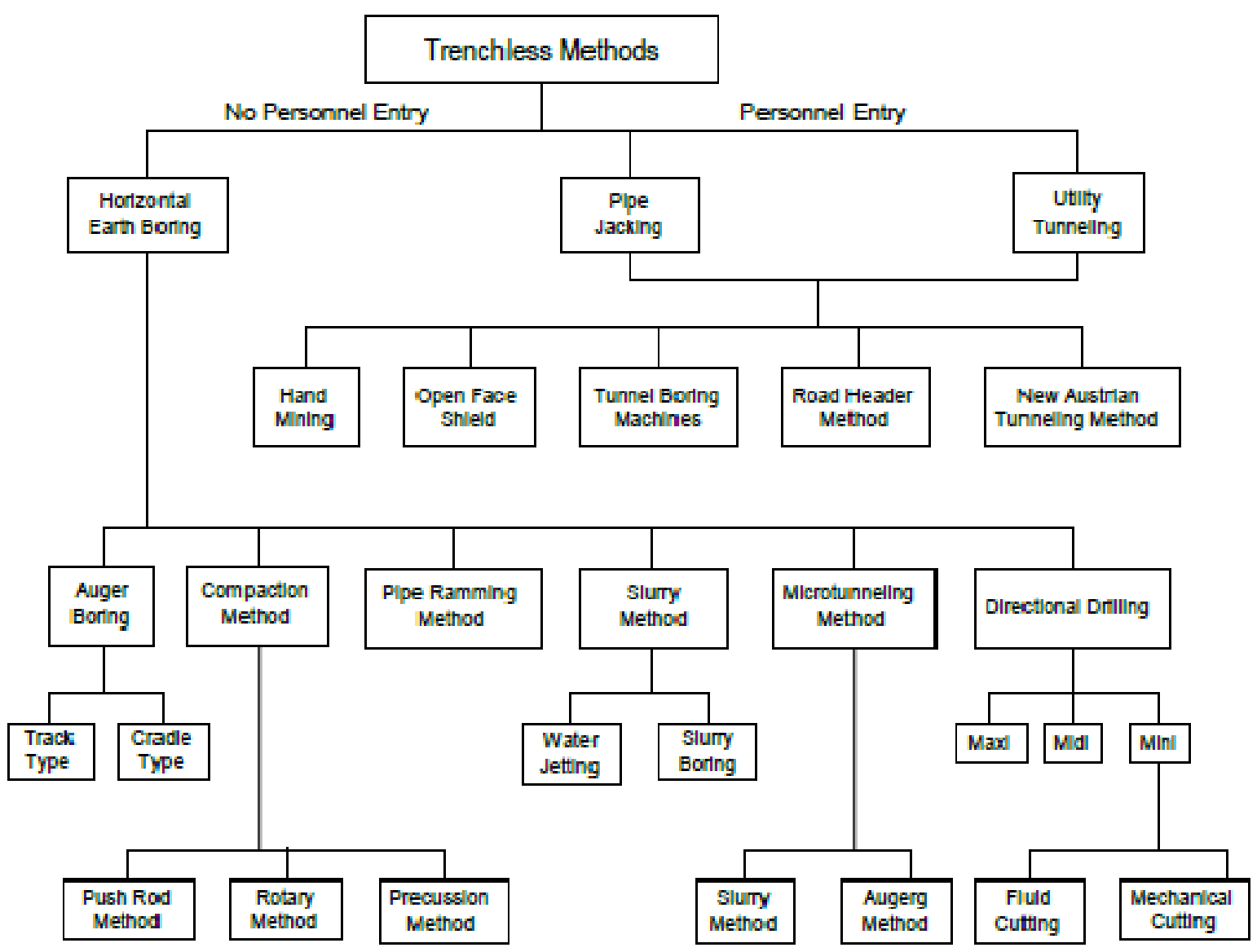

Figure 2: Classification of trenchless technologies [1] 


\subsubsection{Trenchless Construction Methods (TCM)}

Trenchless construction methods (TCM) are a family of methods that are used to install new underground utility pipe involving limited amount of surface disruption much less in comparison to open-cut methods. Some of the trenchless technologies have been used for the installation of conduits for decades. For example, Auger Boring (AB) has been used since the 1940s and Pipe Jacking (PJ) has been used since the early 1900s. Since then, many new trenchless techniques have been introduced and much advancement has taken place with the more traditional techniques. Figure 2 shows the classification of trenchless construction methods [1, 10].

This system segments the industry into three major categories: (1) Horizontal Earth Boring (HEB); (2) Pipe Jacking (PJ); and (3) Utility Tunnelling (UT). Horizontal earth boring includes methods in which the borehole excavation is accomplished through mechanical means without workers being inside the borehole. Horizontal auger boring, also known as "jacking and boring", is one of the oldest trenchless methods, and is also one of the most cost effective according to the North American Society for Trenchless Technology [13]. Auger boring is known to be the most widely used trenchless method for installing steel pipes and casings [14]. Horizontal auger boring is suitable for a variety of soil conditions, but experiences the most difficulty in sands below the water table [15]. Guided auger boring is not recommended for use in soils with boulders, because the pilot tubes could be deflected. Also, guided boring is not recommended in sands below the water table because of the possibility of settlement due to water flowing out of the soil through the pipe [16].

Both PJ and UT techniques require workers inside the borehole during excavation and casing installation process [11]. During the pipe jacking process, the set survey points and settlement gauges were monitored for changes in elevation. This is to make sure that all points exhibited less than 0.2 ' change in elevation, which is the minimal amount of settlement to be expected with a new pipe jacking installation [17]. Man-entry tunnel boring machines (TBMs) and remotely-operated microtunnel boring machines (MTBMs) are two methods that may be used for line and grade critical pipelines greater than 42 inches in diameter [18].
In highly permeable granular soils, TBMs may be unable to control any groundwater inflows and would require dewatering or ground treatment for the bore to proceed. The primary geotechnical concern when performing utility tunnelling is accurately describing and predicting soil behaviour at the face of the tunnel. Particularly, the presence of boulders and saturated sandy soils can be problematic [19]. TBMs also possess an advantage over MTBMs in certain soil conditions because of the operator's ability to access the face of the bore, which is not possible in microtunneling. This ability can be useful when encountering cobbles and boulders. Personnel can access the tunnel face where cobbles and boulders can be removed or broken down with hand tools and removed in pieces [18].

Horizontal directional drilling is a trenchless construction method utilizing a drilling rig to install pipelines beneath obstructions such as roadways, driveways, historical areas, landscaped areas, rivers, and streams [20]. HDD is effective in a variety of ground conditions, but installation is generally faster in clay soils than in sands. HDD is not effective for soils with a significant number of cobbles and boulders, however, because they can deflect the bore and potentially damage the pipe as it is pulled into place [21]. Various reamer types exist, such as the barrel, blade, delta, fluted, fly cutter, and spiral reamer. Each reamer type is designed to be appropriate for particular soil conditions. A barrel reamer is used in soft conditions as it assists in creating stable borehole walls. A blade reamer is used in normal sands and clays and come in sizes up to 26 inches in diameter. A delta reamer is a type of blade reamer that has been optimized for harder soil conditions such as stiff clays. A fly cutter reamer is used for still harder soil conditions, such as sandstone and siltstone. A fluted reamer is suitable for most ground conditions, although it has a risk of "balling up" in clay formation if an improper drilling fluid is used. A spiral reamer is used for loose conditions and for stony soil [18].

Pipe jacking is used to install pipe that is greater than $1066.80 \mathrm{~mm}$ (42 inches) in diameter and for lengths up to 457.2 metres (1500 feet). It is suitable for many clay and sandy soils; however the open boring face makes the method inappropriate for installations beneath the water table, particularly in sandy soils, but is inappropriate in slightly weathered or unweathered rock. [22]. Pipe ramming is most commonly used for shallow installations under roads 
and railroads, and suitable for nearly all soil types except solid rock. It is unsuitable at depths below the water table, especially in sands, as groundwater can flow through the pipe and enter the insertion pit. Simicevic and Sterling [23], gave additional detail about pipe ramming. Impact moling is suitable for compressible soils, excluding stiff soils which resist deformation. Loose sands and gravels can be unsuitable for impact moling because of their collapse potentials, and rocky soils can cause the mole to deflect from its course [24]. Pilot Tube Microtunneling (PTMT) is most effective in soft soil conditions, but unsuitable for soil with significant cobbles and boulders because these can impact steering. PTMT can be used above or below the water table [22].

Stuedlein and Meskele [85] observed that, presently there are no existing and proven techniques for prediction of settlement, vibration, driving stresses, soil resistance to ramming, and drivability for pipe ramming installations. By adopting existing drivability, soil resistance, settlement, and vibration prediction models from pipe jacking, microtunneling, and pile driving models and examining their applicability in pipe ramming installations, resulted in new and technology-specific design guidance.

\subsubsection{Trenchless Renewal Methods (TRM)}

Trenchless renewal methods provide a way to extend the design life of current pipe. These methods can be used to replace, rehabilitate, upgrade, or renovate an existing pipeline system. The basic trenchless renewal methods can be categorized into the following types [22]: (a) Cured-in-place pipe (CIPP); (b) Underground coatings and linings (UCL); (c) Sliplining (SL); (d) Modified Sliplining (MSL); (e) In-line replacement (ILR); (f) Close-fit pipe (CFP); (g) Localized repair (LOR) or Point source repair (PSR); (h) Thermoformed pipe (ThP); (i) Lateral renewal (LR); (j) Sewer manhole renewal (SMR).

The selection of these methods depends on the physical conditions of the existing pipeline system. The important factors include pipeline length, type, material, size, type and number of manholes, service connections, bends, and the nature of the problem or problems involved. The problems with an existing pipeline could be structural or non-structural, and could involve infiltration or inflow, exfiltration or outflow, pipe breakage, joint settlement, joint or pipe misalignment, capacity, corrosion, and abrasion problems [22]. Pipe bursting is not appropriate for use in expansive soils, near other underground structures or pipes with point repairs that have used a ductile material as reinforcement, and for pipes with collapsed sections [23].

\subsection{Trenchless Technology and Open-Trench Method}

Open-cut is the traditional excavation method, which is defined as the operation of excavating to the required pipe installation or rehabilitation level and then backfilling upon completion of the rehabilitation work $[25,26,27]$. This method is variously called open-cut, open-trench, utility cut, dig-and install, digand-repair, or dig-and-replace. The open-cut method generates amounts of excavation, based on project size, ranging from a few to millions of cubic meters and is affected by environment. Trenchless technology offers methods by which underground utilities may be installed without damage to overlying pavement, if proper precautions are observed [28]. Trenchless methods also have the potential to save both time and money, and offer lower social costs when compared with open-cut methods. However, the difficulty of quantifying the value of social costs can cause decision makers to under-appreciate the value of trenchless methods [29]. Nevertheless, Rahman et al [86] examined the social cost of a trenchless project by proposing an itemization and quantification of protocol that municipalities can use to make decisions on the life cycle management of infrastructure, and found that social costs can account for up to $400 \%$ of construction costs on certain projects. But Open-cut installations can also carry significant economic disadvantages. The American Public Works Association (APWA) [30] reported that a study conducted in Burlington, Vermont found that the weakening of pavement caused by utility cuts required additional asphalt overlay thickness of 0.75 to 1.5 inches of pavement to compensate. The additional cost was $\$ 522,000$ per year. Additionally, Los Angeles, California reported spending \$16.4 million per year on pavement overlays to strengthen pavements damaged by utility cuts. Also Najafi [22] noted that up to $70 \%$ of the total cost of underground utility projects can be attributed to backfilling, compaction, and the replacement of landscaping and pavement.

As technology and expertise continue to improve for this still maturing industry, it is expected that trenchless technologies will be utilized for increasing numbers of underground utility projects [22]. Trenchless technology methods depend on emerging methodologies for the installation or rehabilitation of 
underground pipelines without disrupting the surface. These technologies have been used to solve underground problems without excavating large quantities of soil [31]. The need for TT methods has become prevalent due to the inherent problems associated with the open-cut method, especially with respect to environmental impact and traffic disruption [27, 32]. Congestion resulting from lane closures can result: (a) Increased level of traffic in alternative routes. (b) Use of minor roads not designed for such level of traffic, which can reduce the engineering life of the road, necessitating remedial construction work to ensure the road remains suitable for use. (c) Increased journey distances result in increased consumption of fuel and hence an increase in carbon emission. (d) Carbon emissions are also considered to be higher with open cut methods when compared to trenchless techniques, largely due to the quantities of materials removed from the site to reinstate the road [33].

Additional advantages of trenchless methods in comparison to open cut methods are listed by several researchers $[8,18,34,35,36]$, as:

(a) Reduction in required surface restoration.

(b) Reduction of damage to adjoining utilities.

(c) Decrease in disturbance to local residents and businesses.

(d) Increase of flexibility in alignment selection.

(e) Increase of flexibility in choosing depth of new installation which may allow more favourable soil conditions to be used.

(f) Less relationship exists between cost and depth of installation.

(g) Reduction in number of utility relocations.

(h) Reduction in the amount of spoil that requires disposal.

(i) Reduction in the need for dewatering.

(j) Reduction in access requirements, which is advantageous in urban settings and under rivers, etc.

(k) Improvement in safety for the public and for job site workers.

(l) Ease of renewal of existing pipelines.

(m) Mitigation of air, water, and noise pollution.

(n) Reduction of the disturbance to traffic flow.

(p) Ability to install pipe in frozen ground during cold weather.

(q) Possibility of increased speed of work.

The American natural gas industry for example, estimates that almost $60 \%$ of their pipes run below pavement [22]. Peters [37] observes that premature distress that is often seen in newly paved utility cuts may include cracks that allow water to enter and soften the base course and cause loss of pavement support which can result in the further deterioration of the pavement. Arudi et al. [38] adds that such problems have a direct influence on the pavement integrity, life, aesthetic value, and drivers" safety. Bodocsi et al. [39] quantifies this by noting that new pavement should last between 15 and 20 years, while pavement over utility cuts exhibits a shortened life span of about 8 years. As comparisons between opencut and trenchless methods can be very complicated in practice, designers may rely upon indirect cost estimating equations, such as those developed by Tighe et al. [40] to quantify the costs associated with traffic delays.

Although trenchless methods have many advantages over open-cut methods, Iseley and Gokhale [1] observed that some trenchless methods carry the risk of subsidence, surface heave, and leaking of drilling fluid. Often, higher risk inherent in a trenchless project when compared to an open-cut project can make a failure considerably more expensive [41].

\subsection{Major Points to Consider when Planning a Trenchless Project [42]}

(a) Product requirements;

(b) Geological information;

(c) Project achievability;

(d) Technology Limitations;

(e) Documentation;

(f) Monitoring;

(g) Risk / minimising risk.

\subsection{Why Consider these Points?}

(a) Safety

(b) Achievability

(c) Constructed to the clients requirements

(d) Minimise risks and issues

\section{TRENCHLESS TECHNOLOGY AND SURFACE UTILITY ENGINEERING}

Surface Utility Engineering (SUE) is responsible for the assessment of the potential impact of trenchless technology on adjacent utilities and other buried infrastructures such as gas, power and fibre optics. This is to prevent collateral damage to such infrastructures, which lead to high cost of projects and inconvenience [43]. But Arioglu et al [44], and Jeong et al [45], provided information on two papers 
presented at No-Dig Conference held at Copenhagen and Montreal respectively, as concept developed by the USDOT Federal Highway Administration to reduce the cost effects of collateral damage during projects involving the highways. There are three main components of the process as stated in ISTT-2006:

\subsection{Subsurface Utility Designating}

This uses surface geophysical techniques to determine the existence and approximate horizontal position of underground utilities. The geophysical techniques include the various methods, such as pipe and cable locators, magnetic method, metal detectors, Ground Penetrating Radar GPR acoustic emission method etc [46].

\subsection{Surface Utility Locating}

This applies minimally intrusive methods of excavation such as vacuum excavation and surveying instruments to allow the precise horizontal and vertical portion of the underground utility line to be documented.

\subsection{Data Management}

Surveying utility information to project tolerances and reducing it onto the project design and construction documents. A critical component of this data management involves analyzing record information with the result of the designating and locating process. Computer Aided Design and Drafting (CADD) and database management techniques are applied to assure the quality, value and utility of the data collected. The most commonly used underground utility designating methods are Pipe and Cable Locators (Electromagnetic method), Elastic Wave methods, and Ground Penetration Radar (GPR). Vacuum Excavation is the most commonly used underground utility locating method in USA. One of the main advantages of any GPR system, is the ability to locate and map non-metallic, non-conducting materials such as plastic pipes, and concrete or clay ware sewers [43]. Utilities are considered essential services without which society cannot live: supply of potable water and disposal of waste is essential for health; while provision of gas, electricity, fibre optic cables and street lighting are considered fundamental services [47].

Denial of potable water, power, gas and telecommunications, and loss of efficient removal of human effluent, would rapidly result in the breakdown in modern living. The breakdown in control of potable and foul water systems in Zimbabwe resulting in the cholera outbreak in 2008 because of run-down infrastructure, burst sewage pipes, water shortages, and a lack of trained sanitation workers forced people to dig unprotected wells, and defecate in public areas, increasing exposure to this water-borne disease [48]. A study by Ashdown [49], showed that about $80 \%$ locations rate was achieved in a remote geophysical utility detection of buried utilities on a control site, where the location of the pipes and cables were known. While, this study was undertaken in 2001, and technology has undoubtedly moved on then, thus improving likely detection rates, consistently detecting $100 \%$ of the buried utilities for all but the simplest of configurations in ideal ground conditions is likely to still be unachievable [20]. Mapping the underworld (MTU) research projects focus on researching and developing the tools required to locate, accurately position and electronically record the data relating to the utilities buried beneath the carriageway. Firstly, the development of resonant RFID tags, which may be incorporated into newly installed pipes, or retrofitted to the surface of existing buried utilities to improve the chances of detection using GPR [50]. Secondly, surveying techniques that allow for the accurate positioning of the buried utilities even in built up environment, where certain surveying techniques can struggle to operate efficiently. Thirdly, to create a single utility location database from the combination data from the utility companies [51].

Kilometres of pipes are buried beneath the earth surface and the monitoring of their integrity is a challenge. Information about their integrity will help the operators in their planning and management of their maintenance regime. Metje et al [52] noted that traditionally, expensive and much localised sensors are used to provide irregular measurement of integrity of the pipes and the quality of their content. They observed that off-the-shell sensors and communication elements could be used in a smart pipe system although further refinements are necessary in order to miniaturise these sensors. They also, identified the challenges in a smart pipes system to be how to power these sensors, and communicate the data to the operators.

Routine monitoring of the planning of its maintenance and existing systems maintain a technology that can warn of impending failure, but lack the accuracy due to certain limitations. Micro-Electro-Mechanical Systems (MEMS) technology has shown its potential 
in many different applications: aerospace, automotive, home entertainment and biomedical to deliver small cost-effective sensors $[53,54,55]$. Research is being undertaken to incorporate sensors into the trenchless technologies to provide look-head capabilities, such as Ground Penetrating Radar (GPR) within horizontal directional drilling (HDD) cutting tools [56], these techniques are still limited in their ability to 'see' through the ground. There is need to investigate the impact of the ground, both on the physical structure of the utilities, and better understanding of the relationships between geotechnical properties and geophysical properties of various type of ground in various conditions.

\section{TRENCHLESS TECHNOLOGY AND GEOTECHNICAL INVESTIGATION}

Undertaking a trenchless project should never been seen as a simple process but should always be seen as "site specific". Geotechnical is one area in which certain characteristics can change rapidly. Knowing the sub-ground structure that the proposed borehole is to be constructed in, can significantly alter the parameters, design and type of construction method, site location, methodology, costs and expected construction time frame needed to complete the project successfully [5].

Geotechnical investigations are performed to ascertain the character and variability of the strata underlying the site of the proposed structure and to assess those properties, which may affect the performance of the structure and the choice of method of construction $[57,58]$. It is performed to evaluate those geologic, seismologic, and soils conditions that affect the safety, cost effectiveness, design, and execution of a proposed engineering project. Insufficient geotechnical investigations, faulty interpretation of results, or failure to portray results in a clearly understandable manner may contribute to inappropriate designs; delays in construction schedules, costly construction modifications, and use of substandard borrow material, environmental damage to the site, post construction remedial work, and even failure of a structure and subsequent litigation.

In the mid to late 1990s, the horizontal directional drilling (HDD) market was exploding, due mostly to rapid growth in telecom and construction of the fiberoptic backbone across the United States. Unfortunately, as the industry expanded quickly, problems arose from a combination of inexperienced drillers, inadequate geotechnical investigations and a lack of established good practices. In 1998, the California Department of Transportation (Caltrans) expressed concern about potential damages from HDD installations beneath its roadways and considered enacting regulations requiring training for horizontal directional drilling contractors drilling under state lands [59]. Those individuals performing geotechnical investigations are among the first to assess the physical setting of a project. Hence, senior-level, experienced personnel are required to plan and supervise the execution of a geotechnical investigation. Geotechnical investigations are to be carried out by geotechnical engineers, engineering geologists, geological engineers, and geologists and civil engineers with education and experience in geotechnical investigations.

The critical component in determining what trenchless methods can be used is a thorough geotechnical investigation. The types of soil involved, the groundwater conditions, and the presence of large boulders or debris within the fill are all-important factors in determining method. Success with trenchless methods is very dependent on a more intensive site investigation with appropriate planning, design, and installation methods than would be required with open excavation methods [28]. Geologic conditions at a site are a major influence on the environmental impact and impact mitigation design, and therefore a primary portion of geotechnical investigations is to observe and report potential conditions relating to environmental impact $[57,60]$. The complexity and limited access to the soil/boring tool interface make trenchless construction methods significantly more sensitive to adverse ground conditions than traditional open-cut methods [61]. Temple and Stukhart [62], noted unexpected subsurface conditions as the leading source of project delays, disputes, claims, and cost overruns for underground construction projects. Thus, a successful trenchless construction project requires thorough knowledge of the subsurface conditions [61]. Trenchless projects require the contractor to possess sufficient subsurface information to select appropriate construction methods and to prepare for likely obstacles [18]. The quality and volume of geotechnical information available during the design and bidding stages of trenchless projects has a significant impact on the selection of construction methods. The estimated production rates, ground movements, jacking forces, shaft design, and maximum drive 
lengths are all dependent on the available subsurface information [63]. The degree of uncertainty over subsurface conditions will manifest itself in the amounts of contingency money included in the bid [18]. But, Ali et al [84] have provided practitioners with a model that justifies their productivity calculation by quantifying subjective factors effect, which will affect their schedule and cost estimation for trenchless projects.

Geotechnical investigations for trenchless projects have three general phases: planning, investigation, and finally reporting. These phases are closely coordinated, and an iterative approach is used as provided by Richardson et. al [64]. Preliminary geotechnical surveys which incorporate existing geological or geotechnical reports, maps, aerial photographs, and depositional history are important tools for the planning stage of a trenchless construction project. Information from the depositional history includes the glaciations of the area, the presence of cobbles, boulders, and gravel. These obstacles have the potential to unexpectedly deflect the path of the bore if they are not accounted for. Additional information includes whether the area is subject to large landslides, and the presence of trees and other objects below ground surface. If the area has seen low energy, meandering streams and rivers, then fine-grained deposits may be expected. While each trenchless project has unique, site specific requirements, Najafi [22] suggests that a survey should be conducted for at least 15.24 meters (50 feet) on either side of the bore path. Najafi suggests that the predesign surface survey should include the following elements:

(a) Work area requirements

(b) Existing grade elevation data

(c) Surface features such as roadways, sidewalks, utility poles

(d) Boring or test pit locations

(e) Waterways and wetlands

(f) Visible subsurface utility landmarks such as manholes or valve boxes

(g) Structures adjacent to the bore path

Najafi [22] divided subsurface investigations into two steps. The first step involves obtaining information about existing subsurface utility locations along the bore path while the second step is the geotechnical subsurface investigation for the trenchless construction project. The geotechnical subsurface investigation gives more precise information on subsurface conditions on the site. Najafi [22] specifies that the steps for subsurface investigation should include the following:

(a) Determining the nature of soil at the site and its stratification

(b) Obtaining disturbed and undisturbed soil samples for visual identification and laboratory tests

(c) Determining the depth and nature of bedrock, if encountered

(d) Performing in situ field tests

(e) Observing surface drainage conditions from and into the site

(f) Assessing any special construction problems with respect to the existing structures nearby

(g) Determining groundwater levels, sources of recharge, and drainage conditions

Najafi [22] summarised methods of geotechnical surveys employed in subsurface investigations as follows:

(a) Ground penetrating radar (GPR). Effective in gravels and sands.

(b) Acoustic (sonar): Useful for determining depth of rock, interfaces between soft and hard deposits, and buried objects.

(c) Geophysical methods: Variations in the speed of sound waves or in the electrical resistivity of various soils are useful indicators of the depth of water table and of the bedrock.

(d) Test pits or trenches. This method is suitable for shallow depths only but allows visual observation over a larger area than is possible with samples from borings.

(e) Hand augers: Suitable only for shallow depths; only disturbed or mixed samples of soil can be obtained in this method.

(d) Boring test holes and sampling with drill rigs: This is the principal method for detailed soil investigations. An accurate description of the subsurface material characteristics based on the "site-specific" conditions is dependent on sampling interval and technique. ASTM D-1586 specified 1.524 metres (5-ft) depth intervals for a typical split spoon samples taken in soft soil.

Limitations of drill vertical boreholes in the conventional geotechnical investigations include:

(a) No continuous picture of underground conditions is developed.

(b) No complete picture of subsurface conditions for horizontal alignments is technically or economically feasible. 
(c) Vertical site characterization techniques cannot reach underneath structures, roadways, pipeline right-of-ways, or environmentally sensitive areas [41].

Horizontal site characterization techniques, that include a family of soil samplers, contact sensing probes, and borehole geophysical tools capable of providing horizontally continuous geotechnical information overcomes the limitations of traditional vertical site investigation methods. These devices are usually advanced into the ground using horizontal directional drilling technology [18]. Horizontal site characterization techniques provide the following advantages [61]:

(a) Economical for the medium-scale microtunneling and tunnelling projects.

(b) Economic feasibility of this method is directly related to the improvements made in the horizontal directional drilling industry.

A technique that is being used more and more for geotechnical investigation is directional core drilling. With directional control over a borehole, it is possible to drill along a defined trajectory, for instance a planned tunnel alignment, while collecting a core sample over the full borehole length. This core gives firsthand information about the rock quality near the borehole, as well as structural information and indications of the amount of water present [65]. In the case of the cavity expansion model, it is important to obtain critical soil characteristics such as density, friction angle and soil cohesion, which are not normally available from geotechnical boring logs alone. There have been many publications in the past emphasizing the importance of conducting appropriate tests to obtain project specific data. A Geotechnical Baseline Report that provides a reasonable interpretation of the geotechnical conditions is crucial for any complex HDD project [66]. In the Capsule Pipeline Field Station west of Columbia, where field-testing of methods other than pipe jacking took place. A geotechnical investigation was conducted to determine the nature of the soil at this location. Accurate and complete geotechnical information serves as a necessary first step towards the evaluation of possible methods that may be used. In the case of the Macon site, determination of possible boulders in the highway fill through which the bore was planned influenced the selection of possible methods. If boulders or used pavement slabs had been found in the fill, pipe jacking would have been extremely difficult or impossible, leaving only the possible options of utility tunneling or pipe ramming [17].

The HDD Good Practices Guidelines [67] covers design issues and problems including several specialized issues that must often be addressed, such as evaluation of hydro fracture risks and evaluation of settlement risks. Hydro fracture and settlement risks present significant concerns to regulatory and permitting agencies that must be addressed in design and construction.

The most suitable soil conditions for pipe ramming are soft to very soft clays, silts and organic deposits, all sands (very loose to dense) above the water table, and soils with cobbles, boulders and other obstacles of significant size but smaller than pipe diameter (soils with cobbles can be in extremely wet conditions, even with running water). Pipe ramming is a little more difficult in medium to dense sands below the water table, medium to very stiff clays, hard clays, highly weathered shale, soft or highly fractured rocks, marls, chalks, and firmly cemented soils. The only soil conditions that pipe ramming are completely unsuitable for is solid rock. However, in rocky ground conditions, a pneumatic tool can be used to punch the pilot hole first and the pipe can be rammed afterwards [23].

As pipe diameter, length of bore, pipe materials, and type of utility affects the construction method chosen, so also do the ground conditions. The locations of the bore relative to the water table, and also the type of soil both have significant impacts on the effectiveness of the various methods [68]. Table 1 summarizes how ground conditions influence the suitability of various trenchless construction methods and this table provides a general guideline on the suitability of common trenchless techniques in different soil types. Table 1 indicates that loose sand, dense sand below the water table, soil with cobbles, and significantly weathered rocks provide the most significant challenges for most trenchless construction techniques. Medium to very stiff clays and silts, and medium to dense sands above the water table are the only soils that are suitable for all trenchless construction methods.

Allouche et al. [61] presented a methodology for the selection and deployment of horizontal site investigation techniques in trenchless construction projects along with lists of the different state-of-theart devices available. 
Laboratory tests on the recovered soil samples that provide the following soil information as part of preliminary investigation should be determined [22]:

(a) Standard classification of soils

(b) Gradation curves on granular soils

(c) Standard penetration test (SPT) values where applicable (generally unconsolidated ground)

(d) Particle size distribution, including presence of cobbles and boulders

(e) Shear strength

(f) Atterberg limits (liquid, plastic, and shrinkage limits)

(g) Moisture content

(h) Height and movement of water table

(i) Permeability

(j) Cored samples of rock with lithologic description, rock quality designation, and percent recovery

(k) Unconfined compressive strength for representative rock samples (frequency of testing should be proportionate to the degree of variation encountered in the rock core samples); and Mohr's hardness for rock samples. Where rock is encountered, it should be cored in accordance with ASTM D-2113 to the maximum depth of the boring

(l) Presence of contaminated soils (hydrocarbons, etc.)

Final geotechnical investigation report should contain a Geotechnical Baseline Report (GBR) which provides in the industry standard the following [22]:

(a) A common understanding for bidding on the project

(b) A contractual statement of the geotechnical conditions anticipated to be encountered during underground or subsurface construction.

(c) Allows the contractor to make bids using reliable information.

The design recommendations are sometimes used by the contractor in a way not intended by the design engineer; consequently the new approach removes the design information out of the above reports and incorporates a separate design report which is excluded from the contract [64].

\subsection{Trenchless Technologies and Surrounding Soils [18]}

The effect of different trenchless methods on the surrounding soil is a topic that is still being studied. This has led many owners to prefer open-cut method for projects that better suited to trenchless methods due the uncertainty of what problems might be encountered underground. Trenchless construction methods are considered to carry a level of risk for soil related problems. The primary subsurface risks associated with trenchless construction are:
(a) Heave,
(b) Subsidence,
(c) Frac-out,
(d) Collision with underground obstacles.

Frac-out is a common term for the hydraulic fracture of the borehole walls due to drilling fluid pressure. Hydraulic fracture occurs when fluid pressures within the borehole exceed the shear strength or undrained cohesion of the strata [69]. Different models have been developed to simulate and predict borehole pressures [70]. Soil settlement may occur mainly as a result of loss-of-soil occurring during tunnelling and because of dewatering operations that lead to subsidence. In a trenchless technology project, loss-ofsoil may be associated with:
(a) Soil squeezing,
(b) Fluid running or flowing into the heading,
(c) Soil losses due to the size of overcut,
(d) Steering adjustments.

The actual magnitudes of these losses are largely dependent on:
(a) The type and strength of the soil,
(b) Groundwater conditions,
(c) Size and depth of the pipe,
(d) Equipment capabilities,
(e) The skill of the contractor in operating and steering the machine.

If passive earth pressure is exceeded, heave of ground surface may occur, causing damage to nearby utilities and other structures. HDD is susceptible to subsurface deformations due to:
(a) The method's use of drilling fluid and,
(b) The presence of some radial soil displacement.

Allowable drilling pressures and ground improvement protections are considered by researchers [18] to be primary mitigation tools. Cavity expansion theory can be used to create a model that provides a quantitative assessment of drilling fluid limit pressure and minimum depth of cover requirements [71]. The effects of radial soil displacement from trenchless construction can have different significance based on the type of adjacent structure and its position. Boring that expands soil radially alters the stress state of the soil. The following affect the induced stress and strain:
(a) The underground conditions,
(b) Diameter of new tunnels, 
(c) Types of existing pipe (different types of pipe have different sensitivities to movement; for example, asbestos-cement pipes are particularly sensitive, while HDPE pipes are not),

(d) The general underground orientation.

Different methodologies exist to try to model this action using cavity expansion theory such as those outlined in Marshall and Knight [72] and Hunter [73].

During trenchless construction that uses a jacking force to advance the pipe and cutter head, surface subsidence mainly occurs due to a lack of driving force. Excessive driving force, however, can cause surface heaving if soil is being excavated faster than it can be removed. Additionally, the overburden pressure due to the depth of the pipe is important in determining the proper driving force that will not lead to surface deformations [74]. Trenchless rehabilitation methods are considered to have little to no effect on the existing soil, with the exceptions of pipe bursting and pipe splitting. These methods both expand the soil outward, so it is important for the designer to understand and predict ground displacements when considering safe distances to existing underground structures and overlying pavement. Chapman et al [75] shows that an elliptical expansion of the soil best represents the effects of pipe splitting.

\subsection{Principal Objects of Site Investigation}

- To determine the sequence, thickness and lateral extent of the soil strata, and where appropriate the level of bedrock

- To obtain representative samples of the soil (and rock) for identification and classification as well

Table 1. Ground conditions and suitability of trenchless road crossing methods [13]

\begin{tabular}{|c|c|c|c|c|c|}
\hline Ground Conditions & $\begin{array}{l}\text { Guided } \\
\text { Boring }\end{array}$ & $\begin{array}{l}\text { Auger } \\
\text { Boring }\end{array}$ & $\begin{array}{c}\text { Pipe } \\
\text { Ramming }\end{array}$ & $\begin{array}{c}\text { Horizontal } \\
\text { Directional Drilling }\end{array}$ & $\begin{array}{c}\text { Pipe } \\
\text { Jacking }\end{array}$ \\
\hline Soft to very soft clays, silts \& organic deposits & $\mathrm{Y}$ & $\mathrm{Y}$ & $\mathrm{Y}$ & $\mathrm{Y}$ & $\mathrm{M}$ \\
\hline Medium to very stiff clays and silts & Y & Y & Y & Y & Y \\
\hline Hard clays and highly weathered shales & Y & M & Y & Y & Y \\
\hline Very loose to loose sands above water table & M & Y & M & Y & M \\
\hline Medium to dense sands below the water table & $\mathrm{N}$ & $\mathrm{N}$ & Y & Y & $\mathrm{N}$ \\
\hline Medium to dense sands above the water table & Y & Y & Y & Y & Y \\
\hline $\begin{array}{l}\text { Gravels and cobbles less than } 50-100 \mathrm{~mm} \\
\text { diameter }\end{array}$ & $\mathrm{Y}$ & $\mathrm{Y}$ & M & M & $\mathrm{Y}$ \\
\hline $\begin{array}{l}\text { Soils with significant cobbles, boulders, and } \\
\text { obstructions larger than } 100-150 \mathrm{~mm} \text { diameter }\end{array}$ & M & $\mathrm{Y}$ & M & $\mathrm{N}$ & M \\
\hline $\begin{array}{l}\text { Weathered rocks, marls, chalks, and firmly } \\
\text { cemented soils }\end{array}$ & $\mathrm{Y}$ & M & Y & Y & M \\
\hline Slightly weathered to unweathered rocks & Y & M & M & M & $\mathrm{N}$ \\
\hline
\end{tabular}

Key: Y - Yes - Generally suitable by experienced contractor with suitable equipment

$M$ - Marginal - Difficulties may occur, some modifications of equipment or procedure may be required

$N$ - No - Substantial problems, generally unsuitable or unintended for these conditions. as for use in laboratory tests to determine relevant soil parameters.

- To identify the ground water level, the factors, this may cause changes in the water level, and the expected minimum and maximum elevations of the water table.

- To determine whether corrosive media may be formed in the foundation soils due to the penetration of chemicals.

- The various physical and geological processes, which may take place in the chosen site area, have considerable effect on both the substructure and superstructure. These are land slide, soil subsidence (typical of loessial soils when they get wet and of permafrost when it thaws out), soil erosion, shrinkage and swelling of soils due to changes in the climatic and geological conditions of the site, seismicity which may cause the liquefaction of saturated sands, and so on.

- The general topography of the site as it affects foundation design and construction e.g. surface configuration, adjacent property, the presence of water courses, ponds, hedges, trees, rock outcrops etc and available access for construction vehicles and plant. In the case of adjacent properties, the designer must know the time of their construction and the specific features of their foundation in order to be able to tell how much the new and existing building are likely to affect one another. 
- Location of buried services such as electric power and telephone cables, water mains and sewers

- The previous history and use of the site including information on any defects or failure of existing or former buildings attributable to foundation conditions.

- Determine the location of bedrock. The quality of bedrock may also be determined, but this is done only when necessary due to the excessive costs of rock, compared with soil drilling.

\subsection{Factors Influencing the Selection of Methods of Investigation [60]}

(a) Nature of subsurface materials and groundwater conditions.

(b) Size of structure to be built or investigated.

(c) Scope of the investigation, e.g., feasibility study, formulation of plans and specifications.

(d) Purpose of the investigation, e.g., evaluate stability of existing structure, and design a new structure.

(e) Complexity of site and structure.

(f) Topographic constraints.

(g) Difficulty of application.

(h) Degree to which method disturbs the samples or surrounding grounds.

(i) Budget constraints.

(j) Time constraints.

(k) Environment requirements/consequences.

(l) Political constraints.

\section{CASE STUDIES OF IMPACT OF GEOTECHNICAL ON TRENCHLESS TECHNOLOGY}

"In terms of geology, you have topsoil and soft clay on top, and then you can go into cobble and rock formations of sandstone and shale," Hockran says. "The same geological formations that created the market [for shale gas] also create the challenges of drilling here." [76]. The study will be undertaken using materials obtained from the web site of Trenchless Advisor Pty, Ltd on some project executed by the company and made available online.

\subsection{Tarrawanna Project Review}

Trenchless Advisor [77] carried investigation into the Tarrawanna project and found that the ground conditions are fill, sandy clays, sandstone and the environmental factor was creek crossing. The result showed that the HDD contractor along with a list of unacceptable work practices employed inadequate drill rig and methodology. There was lack of information regarding the previous attempts, many unknowns still existed including actual alignment, how many attempts were made and how many were not grout filled were not documented.

Trenchless Advisor provided the client with a trenchless feasibility and concept design for the proposed creek crossing and installation of the required conduits. The feasibility and concept design took into account the recent geotechnical investigation results based on a borehole on either side of the creek and one near the zone substation to give an indication of the subsurface conditions. It also took into consideration the existing utilities, previous under bore attempts, risks and impacts, construction method, creek depth along with the achievable entry and exit set up angles and technical specifications along with the clients cabling requirements. Daily project monitoring reports were completed and sent to the client after every site visit.

The HDD contractor, using an All-Terrain machine fitted with a PCD bit, successfully completed the pilot bore with some hard and difficult rock encountered though this was expected. The hole was then opened to the final size of $500 \mathrm{~mm}$ using both a barrel reamer through the clay and a PCD reamer through the harder rock. The project was successfully completed with little deviation to Trenchless Advisor's concept design with no environmental incidents.

\subsection{Lakes Entrance Project Review}

Trenchless Advisor's [78] review of the Lakes Entrance Project showed that the ground conditions are Marina sands and rocks with major challenging environmental factors as River mouth crossing and bird breeding colony. It was discovered that little to no pre-designed works for all HDD bores were undertaken, minimal to no documentation including methodology, bore plans had be made available and little to no geotechnical investigation including the depth of the man-made wall had been complied. Product pipe that was also already laid out at the exit site and butt welded together had been damaged and some sections were in need of replacement. The previous bores were not deep enough and the drill head had drilled into boulders. This cause some ground engaging tooling to be lost or badly damaged and was not the preferred location for the proposed pipelines. 
With the use of a $375,000 \mathrm{lb}$ HDD machine, appropriate down hole tooling, wire-line system and recycler along with experience and knowledge within sandy ground conditions, the HDD contractor completed the bores as per the client's requirement. One major challenge was the weather and the sea that constantly reclaimed areas that had been established for construction site. Each morning both the exit and entry sides had to be reviewed and investigated due to possible erosion by the sea. Application of good monitoring program, with the correct pre-planning, documentation, understanding of the equipment's practicality and achievability, the project was successfully completed.

\subsection{Jewells Swamp Project review}

The original details of the Jewells Swamp Project review [79] had limited geotechnical information surrounding the wetlands including unknown subground condition. An indicative trenchless design was provided which involved a DN300 PVC Class 12 pipe to be installed using Auger boring or Microtunneling on a grade of $0.5 \%$ over its total distance. The approach required both an entry and exit pit at a depth of approximately $5 \mathrm{~m}$ to achieve the desired depth of 3 to 3.5 metres under the swamp. This project noted within its tender documentation that, "Jewells swamp was identified as a coastal wetland under the provisions of State Environmental Planning Policy No14 (SEPP 14). The crossing of the wetland for the installation of the sewer rising main shall be achieved by Trenchless technology. No excavation or construction activities shall be undertaken inside the designated wetland, or within $2 \mathrm{~m}$ of its boundary. All practicable means must be used to prevent release of water, sediment, drilling fluid or any other material into the wetland."

The contractor understood the difficulty of the project, current design and its potential environmental problems and asked Trenchless Advisor to assess the current design, construction achievability and overall undertaking of the project. A comprehensive geotechnical investigation involving additional geotechnical boreholes to better understand the geology of the area, revealed variable ground conditions up to 15 metres deep and all the four geological boreholes showed different ground conditions and it is difficult to get suitable soil samples due to poor ground conditions. These varied from gravel, fine silty sands, clays, shale and rock. One borehole showed no results for the first eight metres due the water charged ground and silty sands. These unstable soil conditions increased the potential of Frac-out occurring during the drilling and pipe installation process.

Based on the severe conditions of the soil, detailed methodology, environmental and safety requirements, HDD due to its surface launch (shallow pits) and steering capability was chosen. A comprehensive drill additive program, including drill additive contingencies, proper work practices required by the chosen HDD contractor, reamer selection, pullback and rotation speeds, and safe boring depths to minimise any potential Frac-out occurring. The critical buckling pressure coupled with the current pumps achievability, a DN355PE100PN16 polyethylene pipe was recommended with no grade as the pipe was a rising main. A good monitoring program that kept a record of day to day undertakings during its proceedings was followed by the Trenchless Advisor and this ensured that all issues were understood and met, resulting in the successful completion of the project.

\subsection{Kingswood Rail Project Review}

When planning a new route for underground infrastructure project, there are always risks to be mitigated, approvals to be obtained and issues to be rectified before proceeding especially when they involve the crossing of some major existing infrastructures such as road or rail. Trenchless Advisor [80] demonstrated these in the Kingwood Rail Project. On-site discussions were held and requirements needed to gain approval to cross the rail corridor using trenchless technology were outlined: detailed trenchless feasibility and concept design report; methodology, technical drawings as well as other required documentations. Then followed by the selection of the most effective and appropriate trenchless method. Trenchless Advisor undertook the sourcing, pricing, managing the appropriate subcontractors to organise the surveys, existing utility investigation, and geotechnical investigation involving a borehole on either side of the rail corridor to give an indication of the surface conditions. A detailed existing utility search was also undertaken allowing a true mapping of all assets in the area.

These will help in accurately assessing the chosen method and depths required for the under bore and prediction of possible settlement and design of a track-monitoring plan to be followed during construction. The feasibility and concept design report 
took into account geotechnical investigation results, existing utilities, risks, and impacts, construction method and technical specifications along with the current Rail Authority, client requirements and Australian standards. Preliminary electronic bore plan that will ensure the bore's achievability was prepared using expected ground conditions, existing utility location, preferred entry and exit sites as well as all specifications and requirements put forward by the rail authority. Others include appropriate Australian standards, HDD machine requirements, bend radius, and bore depths and product specifications to ensure a safe and practical design was achievable.

Preliminary investigation results showed that a HDD method effective and appropriate for the requirements and that ground settlement prediction based on the ground conditions (silty clay, fine gravel, shale and ground water), depth below rail and method of installation were shown as being limited to approximately $1.0 \mathrm{~mm}$. An in depth assessment of the HDD method incorporated with predicted settlement analysis, planned installation of the bores and the track monitoring planned for construction show that under bores could be achieved with minimal risks.

\subsection{Gillieston Heights Project Review}

The case Gillieston Height Project was unsuitable ground conditions, potential risk of a frac-out and heaving occurring during the drilling and installation process, limited geotechnical information, unpredictable weather patterns, restricted access, existing infrastructure and waterlogged land, varying location (height and width) of the UPVC (Rising Main), can make pipe installation extremely difficult no matter what the construction method used. This particular pipeline was completed using HDD was confronted with all these problems.

To keep the bores achievable, Trenchless Advisor [81] divided the project into two main bores of 300 metres and 650 metres. The incorporated into the bores a minimum depth of 5 metres due to soft ground conditions, in order to minimise the risk of frac-out , allow achievable steer-ability of the drill head and reduce any conflict and ground heaving with the exits UPVC Rising Main which needed to be protected at all time. But the HDD contractor with good experience in within HDD industry, knowledge and professionalism, submitted a methodology and design that called for three bores. After several revisions, an acceptable methodology and design was approved for construction.
Geotechnical showed silty clay but areas of sand, gravel and cobble not indicted on the geotechnical report were encountered but with the expert help of Bariod fluid engineers' pipe was successfully installed. Another problem was the presence of soft alluvial formations and rock ground conditions. This led to the relocation of the Drilling Rig to proposed exit side of the bore to allow successful completion of the pilot bore without casing installation. Reaming and pipe installation was successfully completed.

The key to a successful trenchless project can usually be attributed to an array of different information, issues and understandings. These include correct design, product, and knowledge of the ground conditions, understanding the limitations of technology, comprehensive tender documentation, monitoring of the project and of cause the selected contractor. Trenchless Advisor [42] noted that knowledge is all about minimising risk and the subground conditions being a known can be a major risk. Proper geotechnical investigation results in the following:

- Gives the contractor confident to plan for the job appropriately including costs.

- Selection of appropriate drilling equipment

- Selection non-standard equipment or material to deal with the expected ground conditions such as cobble.

- Selection of back fill materials

- Dewatering requirement

- Planning for off-site disposal of spoil

- Reduction in the risk of unforeseen ground conditions and the potential for accident

Trenchless Advisor [5] noted issues that can arise from changing ground conditions as follows:

- Borehole collapse

- Frac-out (when pressure in a borehole increases and finds an alternative path to the surface, usually directly up)

- Ground settlement

- Ground heaving

- Collapse of excavation pits

- Borehole deviation

- Damaging, jamming or lose of ground engaging tooling

- Damage or collapse of product pipe during installation or once in place

- Piping due to incomplete compaction around the pipe

Schrank et al [82] incorporated a good geotechnical report to successfully undertake Pipe Ramming under 
three active Railroad lines in difficult soil conditions, because the area is primarily underlain by highly heterogeneous glaciofluvial sediments that have been locally reworked by the Skykomish River. These glaciofluvial sediments consist mainly of sand and gravel and underlie a generally thin layer of topsoil and/or fill. Based on explorations of the area, the fill was determined to be up to $1.5-\mathrm{m}$ ( $5-\mathrm{ft})$ deep, consisting of loose-to-medium dense silty sand with a variable amount of organic matter and construction debris. The native soils underlying the fill consist primarily of sand, gravel, cobbles, and boulders, with shallow discontinuous lenses of silt and clay. All these were incorporated in the "Geotechnical Action Plan, BNSF Skykomish 2008 Remediation [83]," for the project.

\section{CONCLUSIONS}

The following conclusions can be made:

1. Trenchless projects should always be seen as "site specific". Knowing the sub-ground structure that the proposed borehole is to be constructed in, can significantly alter the parameters, design and type of construction method, site location, methodology, costs and expected construction time frame needed to complete the project successfully.

2. It should also take into consideration the previous under bore attempts, risks and impacts, construction method records available in the area under considerations.

3. Design of a track-monitoring plan to be followed during construction.

4. Daily project monitoring reports are to be completed and sent to the client after every site visit.

5. Review of the methodology based on the daily bore records of soil data.

6. Correct geotechnical investigation will lead to development of good monitoring program, with the correct pre-planning, documentation, understanding of the equipment's practicality and achievability.

\section{REFERENCES}

[1] Iseley, T. and Gokhale, S. B. "Trenchless Installation of Conduits Beneath Roadways". National Cooperative Highway Research program (NCHRP) - Synthesis of Highway Practice 242, Transportation Research Board, National Research Council, National Academy Press, Washington, DC, 1997. http://onlinepubs.trb.org/ onlinepubs/nchrp/nchrp_syn_242.pdf. Accessed April, 32013.

[2] American Society for Testing and Materials (ASTM). "Compilation of Standards Related to Trenchless Technology", Baltimore MD, 1999.

[3] NASTT - North American Society for Trenchless Technology, 7445 Morgan Rd. | Liverpool, NY 13090.

[4] Thornton, C. I., Robeson, M.D., Girard, L.G and Smith, B.A. "Culvert Pipe Liner Guide and Specifications". Federal Highway Administration, Central Federal Lands Highway Division 12300 W, Dakota Avenue Lakewood, CO 80228, 2005, pp 3. http://www.cflhd.gov/programs/techDevelopment/hy draulics/culvert-pipe- liner/documents/culvert-pipeliner-guide-july2005.pdf Accessed April 1, 2013.

[5] Trenchless Advisor. "Trenchless Through A Crystal ball", Trenchless Advisor Pty. Ltd. ABN: 15003949835. P. 0. Box 6633, Baulkham Hills BC, NSW 2153 Suite 7, Level 4, 29-31 Solent Circuit, Baulkham Hills, NSW 2153, 2009. Website:www.trenchlessadvisor.com.au

[6] PWTB 420-49-10. Application of Trenchless Technology at Army Installations, Published by the U.S. Army Corps of Engineers, Washington DC, 1999, P 2. http://www.wbdg.org/ccb/ARMYCOE/PWTB/pwtb_42 0_49_10.pdf Accessed April 10, 2013.

[7] Koerner, G. R and Koerner, R. M. Geosynthetic Use in Trenchless Pipe Remediation and Rehabilitation, Geotextiles and Geomembranes, Vol. 14, 1996, p 223.

[8] Stidger, R. W. Trenchless Technology Provides Environmental Advantages. Gas Utility Manager. 47:1 2002 pp 18-19.

[9] Thompson, J. "Pipe Jacking and Microtunnelling". London: Chapman \& Hall. 1993.

[10] Iseley, T. and Tanwani, R. "Trenchless Excavation Construction Equipment and Methods Manual", Trenchless Technology Committee, National Utility Contractors Association (NUCA), Arlington, Va. 1993.

[11] Abraham, D., H. Baik, H and Gokhale, S. B. “Development of a Decision Support System for Selection of Trenchless Technologies to Minimize Impact of Utility Construction on Roadways". Publication FHWA/IN/JTRP-2002/07. Joint Transportation Research Program, Indiana Department of Transportation and Purdue University, West Lafayette, Indiana, 2007. http://docs.lib.purdue.edu/cgi/viewcontent.cgi?article $=1531 \&$ context=jtrp Accessed April 12, 2013.

[12] Najafi, M. “Trenchless Technology Piping: Installation and Inspection", McGraw-Hill Professional Illustration, 2010.

[13] NASTT. "Jacking and boring: quality assurance / quality control". North American Society for Trenchless Technology, No-Dig Conference, 2006. http://www.nastt.org/quickfacts/JackingBoring.pdf Accessed April 12, 2014.

[14] ASCE. "Horizontal Auger Boring Projects". ASCE Manuals and Reports on Engineering Practice No. 106. 
American Society of Civil Engineers. Reston, Virginia. 2004

[15] Munro, A.G. and McMurdie, W.D. "Auger boring for pipeline construction". NO-DIG 1985: Trenchless Construction for Utilities, Proceedings of the First International Conference.1985, pp 109-17.

[16] Fisher, T. 2003. "Guided boring method - case study". Proceedings of the ASCE International Conference on Pipeline Engineering and Construction: New Pipeline Technologies, Security, and Safety. 2. 2003, pp 17631770.

[17] Najafi, M., Gunnink, B and Davis, G. "Preparation of Construction Specifications, Contract Documents, Field Testing, Educational Materials, and Course Offerings for Trenchless Construction". Prepared for the Missouri Department of Transportation Organizational Results Division. P. O. Box 270-Jefferson City, MO 65102, October 2005, pp. 1, 3, 6.

[18] Conway, W. M. "An investigation of trenchless technologies and their interaction with native Iowa soils". M. Sc Thesis, Iowa State University Ames, Iowa, 2008, pp 1-283. http://publications.cce.iastate.edu/bitstream/1234567 89/79/1/G\%20Conway\%20Trenchless\%20Thesis.pdf

[19] Mathy, D. C. and Kahl, R. A. "TBM vs. MTBM: Geotechnical Considerations". Proceedings of the ASCE International Conference on Pipeline Engineering and Construction: New Pipeline Technologies, Security, and Safety. 2, 2003, pp 1261- 1271.

[20] Willoughby, D. A. "Horizontal Directional Drilling: Utility and Pipeline Applications". McGraw-Hill. 2005.

[21] Baumert, M. E. and Allouche, E. N. "Real-time monitoring for quality delivery of directional drilling installations". Journal of Infrastructure Systems. 9:1, 2003, pp 35-43.

[22] Najafi, M. "Trenchless Technology: Pipeline and Utility Design, Construction, and Renewal". Water Environment Federation Press, 2005.

[23] Simicevic, J. and Sterling, R. L “Guidelines for Pipe Ramming”, TTC Technical Report \#2001.04, U.S. Army Corps of Engineers; Engineering Research and Development Center (ERDC); 3909 Halls Ferry Road; Vicksburg, MS 39180; December 2001, p 2. http://www.trenchlessdataservice.com/library/rammi ng.pdf Accessed April 11, 2014.

[24] Clarke, I. "Impact moling and ramming equipment". Nodig International. 15:2 2004, pp 22-24.

[25] Church, H. K. "Excavation Planning Reference Guide”, McGraw-Hill, New York, 1988.

[26] Harbuck, R. H. "Economic Evaluation of Trenchless Technology", In:2000 AACE International Transactions, 44th Annual Meeting, Association for the Advancement of Cost Engineering, Calgary, AB, Canada, 2000, pp $12.1-12.7$

[27] Gangavarapu, B. S. "Analysis and Comparison of Traffic Disruption Using Open-cut and
Trenchless Methods of Pipe Installation", M. Sc Thesis, Michigan State University, USA,2003.

[28] ODOT HYDRAULICS MANUAL. Chapter 16- Trenchless Technology, Prepared by Engineering and Asset Management Unit Geo-Environmental Section 2011, pp 1-38. ftp://ftp.odot.state.or.us/techserv/GeoEnvironmental/Hydraulics/Hydro/Manuals_and_Guida nce/HDM2011/Chapter_16_2011/Chapter_16.pdf Accessed April 11, 2014.

[29] Gangavarapu, B.S., Najafi, M., and Salem, O. 2003. Quantitative Analysis and Comparison of Traffic Disruption Using Open-Cut and Trenchless Methods of Pipe Installation. In New Pipeline Technologies, Security, and Safety. 2. 2003, pp 1714-1724.

[30] American Public Works Association (APWA). Subsurface Utility Engineering: Applications in Public Works. Kansas City, MO. 1997.

[31] Iseley, T., Najafi, M and Tanwani, R. Trenchless Construction Methods and Soil Compatibility Manual, National Utility Contractors Association, Arlington, VA. 1999.

[32] Atalah, A., Chang-Jin, C., and Osburn, K. "Comparison Study of Installing Fiber Optic in

University Campuses Using Trenchless Techniques Relative to Open Cut". In: Pipelines

4-7 August, Cleveland, OH, USA, 2002.

[33] Rogers, C. D. F., Thomas, A. M., Jefferson, I. and Gaterell, M. "Carbon Dioxide Emissions

Due to Highway Subgrade Improvements", Transportation Research Record Vol. 2104, 2009,

pp 80-87.

[34] Barsoom, J. "Trenchless pipeline technology". Standardization News. 23:5 1995, pp 18-23.

[35] Khogali, W.E.I. and Mohamed, E.H. 1999. "Managing utility cuts: issues and considerations". APWA International Public Works Congress NRCC/CPWA Seminar Series "Innovations in Urban Infrastructure." 1999, pp 1-11.

[36] Jung, Y.J. and Sinha, S.K. "Evaluation of trenchless technology methods for municipal infrastructure system". Journal of Infrastructure Systems. 13:2, 2007, pp 144-56.

[37] Peters, T. "City Combats damage to city streets caused by utility cuts". Public Works; 133, 2002, pp 4.

[38] Arudi, R., Pickering, B., Flading, J. "Planning and implementation of management system for utility cuts". Transportation Research Record. 1699; 2000, pp 42-48.

[39] Bodocsi, A., Pant, P. D., Aktan, A. E., Arudi, R. S. Impact of Utility Cuts on Performance of Street Pavements-Final Report. The Cincinnati Infrastructure Institute, Department of Civil and Environmental Engineering, University of Cincinnati, 1995.

[40] Tighe, S., Lee, T., McKim, R., and Haas, R. "Traffic delay cost savings associated with trenchless technology". Journal of Infrastructure Systems. 5:2, 1999, pp 45-52. 
[41] O"Reilly, M. and Stovin, V. "Trenchless construction: risk assessment and management". Tunneling and Underground Space Technology. 11:1 1996, pp 25-35.

[42] Trenchless Advisor. "Trenchless Technology: Planning \& Managing", Trenchless Advisor Pty. Ltd. ABN: 15 003949 835. PO Box 6633, Baulkham Hills BC, NSW 2153 Suite 7, Level 4, 29-31 Solent Circuit, Baulkham Hills, NSW 2153, 2012

[43] International Society for Trenchless Technology (ISTT). "Site Survey and Buried Infrastructure Location", Trenchless Technology Guidelines, Trenchless Technology Resource Centre. Second Edition, May, 2006, $\quad$ pp $\quad 1 \quad-9$. http://www.astt.com.au/images/uploads/06_Site_Surv ey.pdf Accessed March 2013

[44] Arioglu, S., Abraham, N., Zembillas and Halpin, D. "Implementation of Subsurface Utility Engineering Technologies: A Case Study". In Proceedings of 20th NoDig International Conference and Exhibition, Copenhagen, May, 2002, pp 368 - 378.

[45] Jeong, H., Abraham, D. M , Anspach, J. H., Zemballis, N. M., Lew, J. and Halpin, D. Identification of Buried Utilities using Subsurface Utility Engineering (SUE). NO-Dig 2002- sponsored by the North American Society of Trenchless Technology (NASTT), Montreal Canada, April 28-May 1, 2002.

[46] Simi, A., Manacorda, G., Miniati, M., Bracciali, S and Buonaccorsi, A. "Underground asset mapping with dual-frequency dual-polarized GPR massive array". Ground Penetrating Radar GPR) 2010 13th International Conference on , vol., no., pp.1,5, 21-25 June, 2010. doi: 10.1109/ICGPR.2010.5550236.

[47] Royal, A.C.D., Rogers C.D.F., Atkins, P.R., Chapman, D.N., Cohn, A.G., Curioni, G., Foo, K.Y, Goddard, K., Hayes, R., Hao, T., Lewin, P.L., Metje, N., Muggleton, J.M., Naji, A., Orlando, G., Pennock, S.R., Redfern, M.A., Saul, A.J., Swingler, S.G., and Wang, P. "Mapping the Underworld: A Step-Change in the Approach to Utility Location and Designation. ICPTT 2011: Sustainable Solutions for Water, Sewer, Gas, and Oil Pipelines". Proceedings of the International Conference on Pipelines and Trenchless Technology. 2011. http://postgrad.eee.bham.ac.uk/fooky/MTU_StepChan ge_ICPTT11.pdf Accessed April 2013.

[48] British Broadcasting Corporation (BBC). "Cholera outbreak strikes Zimbabwe". Online Article Posted on Friday, $21 \quad$ November, 2008. http://news.bbc.co.uk/2/hi/africa/7742762.stm

[49] Ashdown, C. "Mains Location Equipment: A State-ofthe-Art Review and Future Research Needs" - Final Report. UKWIR Report Number: 01/WM/06/1, ISBN: 1 84057233 7, 2001.

[50] Hao, T., Burd, H. J., Edwards, D. J. and Stevens, C. J. "Enhanced Detection of Buried Assets", Antennas and Propagation Conference, LAPC 2008, Loughborough, 17-18 March, 2008, pp 249-252.

[51] Beck, A. R., Fu, G., Cohn, A. G., Bennett, B and Stell, J. G. "A Framework for Utility Data Integration in the UK," Proceedings of the Urban Data Management Society
Symposium, Coors, V., Rumor, M., Fendel, E. M. \& Zlatanova, S. (Editors), Stuttgart, Germany, Oct. 2007.

[52] Metje, N.; Chapman, D. N.; Cheneler, D., Ward, M and Thomas, A. M. Smart Pipes-Instrumented Water Pipes, Can This Be Made a Reality? Sensors 2011, 11, pp 7455 7475 http://www.mdpi.com/14248220/11/8/7455/pdf Accessed March 2013.

[53] Mahalik, N. P. "Principle and Applications of MEMS: $A$ Review". International Journal of Manufacturing Technology and Management. Vol. 13, No. 2, 2008, pp 324-343.

[54] Tanaka, M. "An Industrial and Applied Review of New MEMS Devices features", Microelectronic Engineering. Vol. 84, 2007, pp 1341-1344.

[55] Richards Grayson, A. C., Shawgo, R. S., Johnson, A. M., Flynn, N. T., Li, Y., Cima, M. J and Langer, R.A "BioMEMS Review: MEMS Technology for Physiologically Integrated Devices", Proc. IEEE, 92, 2004, pp 6-21.

[56] Manacorda, G and Miniati, M. "Optimised Radar to Find Every Utility in the Street Deliverable D21: BoreHead Radar Test Report". Online report, 2010. http://www.orfeus-

project.eu/publications/deliverable_D21.pdf Accessed March 2013.

[57] BS 5930:1999+2:2010. “Code of Practice for Site Investigations". British Standards Institution 2013.

[58] BS 8004:1986. "Code of Practice for Foundations" Formerly CP (2004). British Standards Institution (BSI 10-1998).

[59] Bennett, D and Ariaratnam, S. "How the HDD Good Practices Guidelines has Evolved". Horizontal Directional Drilling Guide; Trenchless Technology Special Supplement, A comprehensive Look at the North American HDD Industry 2011 pp 21-23. www.trenchlessonline.com Accessed April 11, 2014

[60] EM 1110-1-1804. “Geotechnical Investigations", Department of the Army U.S. Army Corps of Engineers Washington, DC 20314-1000, 2001. http://140.194.76.129/publications/eng-manuals/EM 1110-1-1804_sec/EM_1110-11804_Sections/basicdoc.pdf Accessed April 2013.

[61] Allouche, E. N., Ariaratnam, S. T., and AbouRizk, S. M. "Applications of Horizontal Characterization Techniques in Trenchless Construction". Journal of Construction Engineering and Management 127:6, 2001, pp 476-484

[62] Temple, M. W. B. and Stukhart, G. "Cost effectiveness of geotechnical investigations". Journal of Management in Engineering: 3:1 1987, pp 8-19.

[63] Klein, S. J., Nagle, G. S., and Raines, G. L. "Important geotechnical considerations for microtunneling". NoDig Engineering. 3:4, 1996, pp 9-12.

[64] Richardson, T., Younis, M., and Headland, P. "Geotechnical Investigations for Trenchless Technology". Proceedings of the ASCE International Conference on Pipeline Engineering and Construction: New Pipeline Technologies, Security and Safety, Baltimore, MD. 2: 2003, pp 1238-1247. 
[65] Lindhjem, R. Geotechnical Investigation by Directional Core Drilling. Trenchless Technology, September 01, 2009. http://trenchlessonline.com/index/webappstories- action/id.939 Accessed April 11, 2014.

[66] Huli, A., and Doherty, D. "Design Considerations for Intersect Method of HDD. Horizontal Directional Drilling Guide", Trenchless Technology Special Supplement, A comprehensive Look at the North American HDD Industry 2013 pp 18-21. 2014

www.trenchlessonline.com Accessed April 11,

[67] Bennett, D and Ariaratnam, S. The HDD Good Practices Guidelines. Third Edition

[68] Kenny, M.J., Guasti, S., and Zsak, P. “Continuous flight auger boring in sandy soils", BGA International Conference on Foundations, Innovations, Observations, Design and Practice. 2003, pp 433-41.

[69] Lueke, J. S. and Ariaratnam, S. T. "Surface Heave Mechanisms in Horizontal Directional Drilling". Journal of Construction Engineering and Management. 131:5, 2005, pp 540-547.

[70] Ariaratnam, S. T., Harbin, B. C., and Stauber, R. L. "Modelling of annularfluid pressures in horizontal boring". Tunnelling and Underground Space Technology. 22:5-6, 2007, pp 610-619.

[71] Francis, M., Kwong, J., and Kawamura, K. 2003. "Analysis of heave and subsidence risk for horizontal directional drilling". Proceedings of the ASCE International Conference on Pipeline Engineering and Construction: New Pipeline Technologies, Security, and Safety. 2, 2003, pp 1481- 1495

[72] Marshall, A. M. and Knight, M. A. "Surface deformations due to near surface horizontal bores - a laboratory and numerical investigation". Annual Conference of the Canadian Society for Civil Engineering. 2003, pp 23632372.

[73] Hunter, A. "Effect of trenchless technologies on existing iron pipelines". Proceedings of the Institution of Civil Engineers, Geotechnical Engineering. GE3; 2005, pp 159-167.

[74] Shou, K. J., and Chang, F. W. "Analysis of pipe-soil interaction for a miniature pipe-jacking". Journal of Mechanics. 22:3; 2006, pp 213-220.

[75] Chapman, D. N., Chan, A. H. C., Rogers, C. D. F., Wan, S. S. K., Ng, P. C. F. "Predicting ground displacements caused by pipe splitting operations". Proceedings of the ASCE International Conference on Pipeline Engineering and Construction: New Pipeline Technologies, Security, and Safety. 2; 2003, pp 1173-1183.

[76] Kramer, B. Marcellus Buildout. Horizontal Directional Drilling Guide, Trenchless Technology Special Supplement, A comprehensive Look at the North American HDD Industry 2012 pp 18-21. www.trenchlessonline.com Accessed April 11, 2014

[77] Trenchless Advisor. "Project Review: Tarrawanna", Trenchless Advisor Pty. Ltd. ABN: 15003949835.
PO Box 6633, Baulkham Hills BC, NSW 2153 Suite 7, Level 4, 29-31 Solent Circuit, Baulkham Hills, NSW 2153, 2009. www.trenchlessadvisor.com.au

[78] Trenchless Advisor. "Project Review: Lakes Entrance", Trenchless Advisor Pty. Ltd. ABN: 15003949835. PO Box 6633, Baulkham Hills BC, NSW 2153 Suite 7, Level 4, 29-31 Solent Circuit, Baulkham Hills, NSW 2153, 2009. www.trenchlessadvisor.com.au

[79] Trenchless Advisor. "Project Review: Jewells Swamp", Trenchless Advisor Pty. Ltd. ABN: 15003949 835. PO Box 6633, Baulkham Hills BC, NSW 2153 Suite 7, Level 4, 29-31 Solent Circuit, 2009. Baulkham Hills, NSW 2153. www.trenchlessadvisor.com.au

[80] Trenchless Advisor. "Project Review: Kingswood Rail", Trenchless Advisor Pty. Ltd. ABN: 15003949835. PO Box 6633, Baulkham Hills BC, NSW 2153 Suite 7, Level 4, 29-31 Solent Circuit, 2009. Baulkham Hills, NSW 2153. www.trenchlessadvisor.com.au

[81] Trenchless Advisor. "Project Review: Gillieston Heights", Trenchless Advisor Pty. Ltd. ABN: 15003949 835. PO Box 6633, Baulkham Hills BC, NSW 2153 Suite 7, Level 4, 29-31 Solent Circuit, 2009. Baulkham Hills, NSW 2153. www.trenchlessadvisor.com.au

[82] Schrank, J. S., Havekost, M. D. and Njoloma, S. M. Pipe Ramming Under Three Active Railroad Lines in Difficult Soil Conditions. The North American Society (NASTT) and the International Society for Trenchless Technology (ISTT); International No-Dig Show 2009, Toronto, Ontario Canada, March 29 - April 3, 2009, pp 1-10.

http://www.jacobssf.com/images/uploads/09_Schrank -Havekost_Skykomish_NoDig.pdf Accessed April 11, 2014.

[83] Jacobs Associates. "Geotechnical Action Plan, BNSF Skykomish 2008 Remediation," Seattle, WA, March 26, 2008.

[84] Ali, S., Zayed, T., and Hegab, M. "Modeling the Effect of Subjective Factors on Productivity of Trenchless Technology Application to Buried Infrastructure Systems". Journal of Construction Engineering and Management Vol. 133, No. 10, October 1, 2007, pp 743748.

http://users.encs.concordia.ca/ zayed/JOURNALS/26. pdf Accessed April 16, 2014.

[85] Stuedlein, A. W. and Meskele, T. "Analysis and Design of Pipe Ramming Installations". Oregon Department of Transportation Research Section and Federal Highway Administration, November 2013, pp 1-222. http://www.oregon.gov /ODOT/TD LTP RES/docs/Reports/2013/SPR710 PipeRamming.p df Accessed April 16, 2014.

[86] Rahman, S.; Vanier, D. J.; Newton, L. A. "Social Cost Considerations for Municipal Infrastructure Management". NRC Publications Record. May 2005. http://dx.doi.org/10.4224/20377011 